Chemical Analysis of Renal Calculi Date of stone removal or passage Weight

Description

Colcium

Oralate

Phosphorus

Magnesium
Uric acid

Ammonia

Cystine

Ash ..

different areas of the calculus were powdered and photographed with $\mathrm{CuK} \alpha$ radiation. The resulting diffraction patterns did not contain the discrete lines given by crystalline matter. A piece of the stone was then heated for 24 hours in a furnace at $1,000^{\circ} \mathrm{C}$. The $x$-ray powder method showed that this material was crystalline and that it consisted of tridymite, one of the high temperature forms of $\mathrm{SiO}_{2}$ stable between 870 and $1,470^{\circ} \mathrm{C}$ and metastable at room temperature. The calculus therefore consisted predominantly of opaline silica.

\section{Discussion}

The nature of the stone in this case was not suspected for five years despite several missed opportunities for inspired guesses. Firstly, the low radiodensity of the stone (see fig. 1) should have aroused some suspicions. Such low density might be due to cystine or magnesium ammonium phosphate. The former can be readily excluded, however, by the simple nitroprusside screening test, while the latter is most unlikely in the absence of infection of the urinary tract. Secondly, the stone analysis should have disclosed the unusual nature of the chemical composition. Stone analysis, however, is performed rather badly in most hospital laboratories, and, furthermore, such analysis is usually qualitative and not quantitative so that trace constituents can be erroneously reported as main ingredients. This presumably explains why chemical analysis of one of this patient's stones at another hospital showed "calcium, phosphate, and oxalate." Quantitative analysis in our laboratory immediately showed zero or low amounts of the usual constituents. Finally, on handling the stone it was immediately apparent that it had an unusually low density, feeling very light for its size.

On direct questioning the patient admitted that he had had indigestion for many years for which he had taken magnesium trisilicate mixtures after every meal. He is not certain whether this habit had already started in $\mathbf{1 9 4 0}$ or began some time after

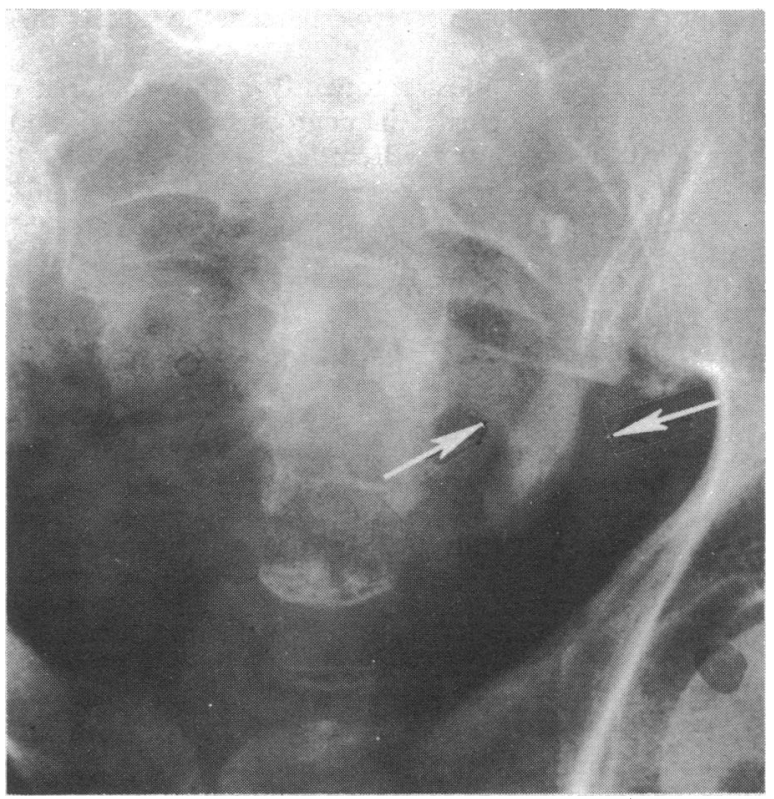

Low density silica calculus in lower end of ureter (arrowed).

this. The equivalent of $2 \mathrm{~g}$ magnesium trisilicate had been taken daily for many years. Such a rate of ingestion would not seem to be unduly excessive, and it seems surprising that more cases of silica stone have not been reported. This may be a reflection on the lack of enthusiasm shown by many hospitals for stone analysis. It is therefore strongly urged that stone analysis should be quantitative, especially since it has been shown by Westbury and Omenogor (1970) that this procedure is actually simpler than qualitative analysis.

\section{References}

Herman, J. R., and Goldberg, A. S. (1960). Foumal of the American Medical Association, 174, 128.

Lagergren, C. (1962). Yournal of Urology, 87, 994.

Herring, L. C. (1962). Fournal of Urology, 88, 545 .

Westbury, E. J. (1972). In preparation.

Westbury, E. J., and Omenogor, P. (1970). Fournal of Medical and Laboratory Technology, 27, 462.

\title{
Tumoral Calcinosis in England
}

\author{
G. SLAVIN， L. KLENERMAN， A. DARBY，S. BANSAL
}

British Medical fournal, 1973, 1, 147-150

\section{Summary}

Two cases of tumoral calcinosis are presented in patients living in England. The clinical and pathological features are described and attention is drawn to the need to consider exotic diseases in patients who have originated from or lived in the tropics.

\footnotetext{
Northwick Park Hospital and Clinical Research Centre, Harrow, Middlesex HA1 3UI

G. SLAVIN, M.R.C.PATH., M.R.C.P., Consultant Histopathologist

L. KLENERMAN, R.R.c.s., Consultant Orthopaedic Surgeon

A. DARBY, M.R.C.PATH., Senior Registrar, Histopathology

S. BANSAL, F.R.C.S., Registrar, Orthopaedic Surgery
}

The cause of tumoral calcinosis is not known. It may be a metabolic disease of obscure aetiology but local trauma often appears to be a factor in its development.

\section{Introduction}

Tumoral calcinosis is an uncommon condition of obscure aetiology which is characterized clinically by lobulated, calcified, cystic masses usually situated near large joints such as the hips, shoulders, and knees and characterized pathologically by fibrous-walled cystic spaces containing structureless calcific debris and associated with a variable inflammatory reaction. It was named by Inclan (1943) who drew attention to the predominant characteristics of soft tissue swellings with massive 
calcification. Palmer (1966) preferred to term the lesion "massive calcinosis."

It has been reported most frequently in the coloured races and most cases have occurred in negroes from Africa and the Americas (McClatchie and Bremner, 1969; Owor, 1972; Lafferty et al., 1965). Another case has been reported from New Guinea (Berg, 1972). Tumoral calcinosis has been described occasionally in whites in the U.S.A. (Riemenschneider and Ecker, 1952; Lafferty et al., 1965). It does not appear to have been reported in the United Kingdom so far.

Maegraith (1971) drew attention to the importation of exotic diseases into Britain by immigrants, and the problems of diagnosis may extend beyond the clinical presentation to those of unusual tissue reactions encountered by pathologists. We describe two cases of tumoral calcinosis in immigrants who presented to this hospital in one year.

\section{Case 1}

A negro boy from Barbados aged 14 years had lived in England for three years. He presented with pain and swelling of his right foot which had been present for seven months and was said to have followed a football injury. His general health sas good and there was no relevant past history.

Examination showed a swelling 7.5 by $5 \mathrm{~cm}$ over the plantar and dorsal aspects of his right foot between the fourth and fifth metatarsals. It was more prominent on the plantar aspect and was fixed to deep structures, but not to skin (fig. 1). Radiographs showed a lobulated calcified lesion over the heads of the fourth and fifth metatarsals. Underlying bones were normal (fig. 2).

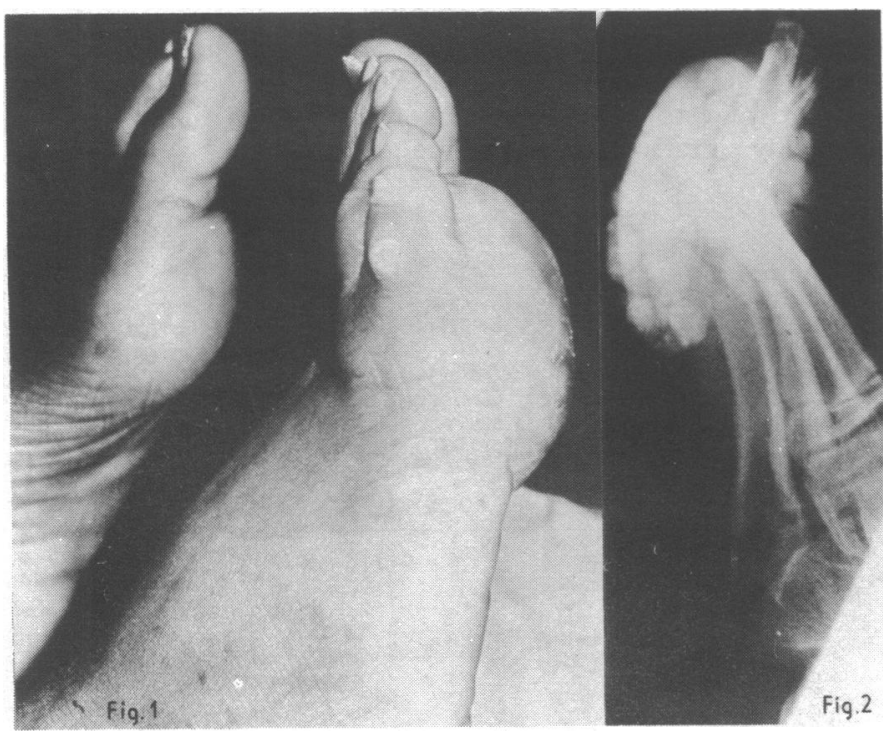

FIG. 1-Appearance of foot showing the pronounced swelling of sole compared with normal size.

FIG. 2-Radiograph showing mass of radio-opaque material in soft tissues.

Other systems were normal and no other swellings were palpable. Relevant chemical estimations made were: serum calcium $2 \cdot 42 \mathrm{mmol} / 1$. (normal 2.20-2.63); serum phosphorus 1.49 mmol/1. (normal 0.2-1.36); and, alkaline phosphatase 26.5 K.A. units (normal 4-11).

At operation the swelling was excised through a continuous longitudinal incision on the dorsal and plantar aspects of the fifth web space. White creamy material discharged from the wound, drying rapidly and leaving a chalk-like powder. Complete excision of the lesion was difficult because there was no clearly defined plane of cleavage.

On examination the material was irregular, firm, white tissue with intervening soft chalk-like areas. Microscopical examination showed cystic spaces lined by thick fibrous trabeculae and containing structureless granular debris which was basophilic and gave a positive von Kossa reaction. There was a well marked chronic inflammatory reaction in which round cells were prominent; foreign body type giant cells were frequent around the calcific material. The appearances of the lesion were characteristic of tumoral calcinosis as seen in Africans (figs. 3 and 4).

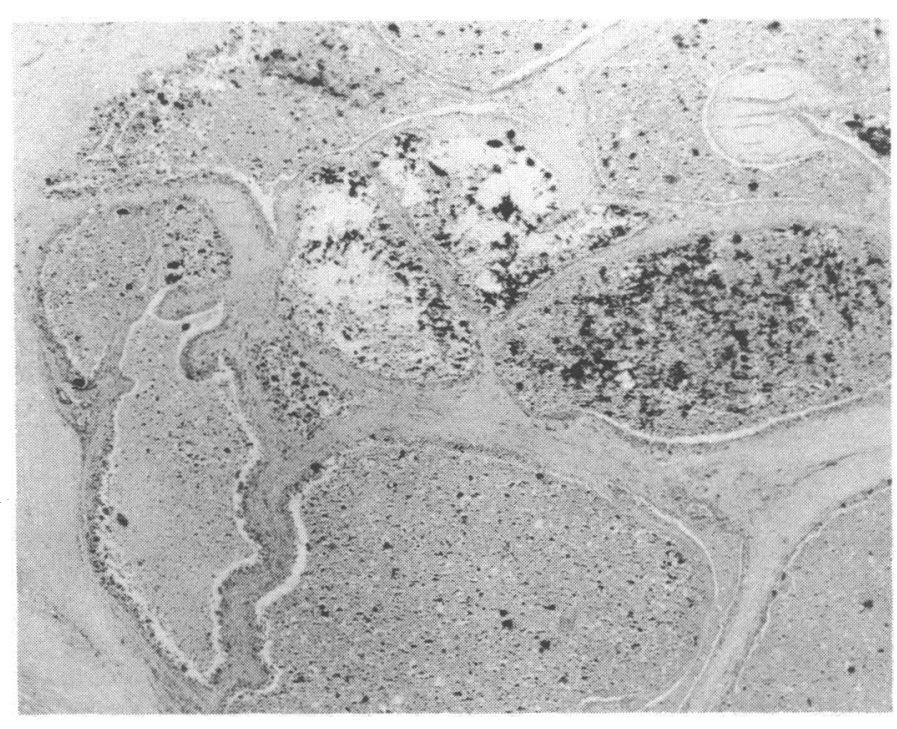

FIG. 3-Fibrous trabeculae surrounding cavities filled with basophilic granular debris. (Haematoxylin and cosin. $0 \times 39$.)

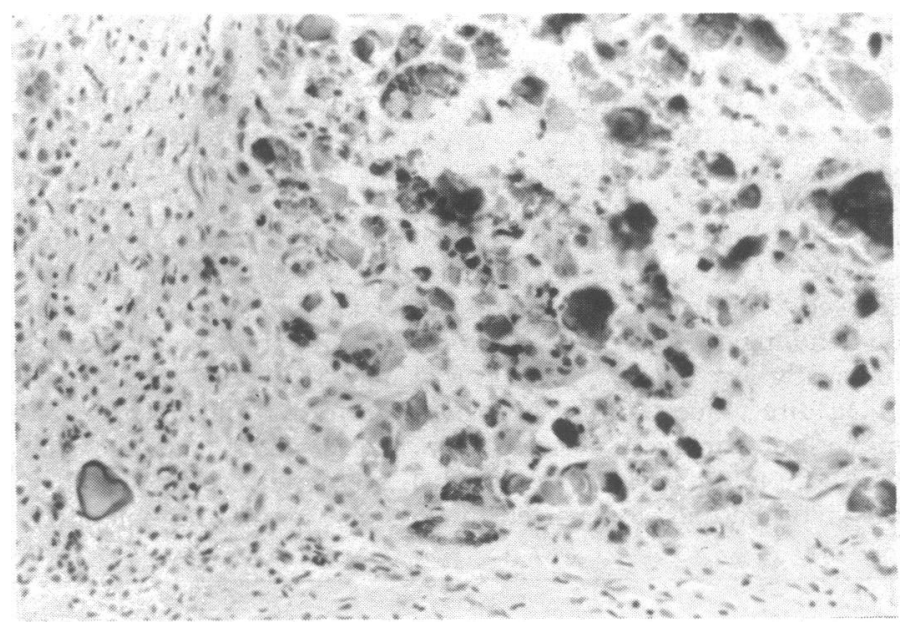

FIG. 4-Numerous foreign body type giant cells are noted in association with calcific debris. (Haematoxylin and eosin. $0 \times 233$.)

After operation the wound healed well. There was no recurrence of the lesion after 18 months but the biochemical abnormalities in the serum remained unchanged. Chemical analysis of the chalk-like material showed it to be calcium phosphate. Three siblings of the patient were examined; no lesions were seen but biochemical estimations showed that though the calcium and alkaline phosphatase levels were normal the serum phosphorus level was increased in each case- $1.66,1.60$, and $1.56 \mathrm{mmol} / 1$. respectively.

\section{Case 2}

A 29-year-old male Indian immigrant from Uganda had lived in Harrow for two years. He complained of a hard lump in his left buttock which had discharged intermittently for two years. No history of trauma or of injections in this site was obtained. There was a small punctate lesion on the left buttock surrounded by an area of induration $3 \mathrm{~cm}$ in diameter and extending into the subcutaneous tissue. No other lesions were noted and systemic examination was normal. The lesion was excised under local anaesthesia.

Microscopical examination showed a mass of degenerate structureless material beneath the epithelium occurring in solid islands with 
basophilic areas of calcification surrounded by granulation tissue and fibrous trabeculae. There was a noticeable inflammatory reaction, with many foreign body type giant cells. The features were characteristic of tumoral calcinosis.

After operation the wound healed well and there was no recurrence after 12 months. Serum calcium, phosphorus, and alkaline phosphatase estimations made after the tissue diagnosis were normal. It was not possible to examine relatives of this patient.

\section{Discussion}

Tumoral calcinosis is an uncommon disease which occurs predominantly in coloured races but with occasional reports in white patients. It occurs equally in males and females and at all ages. It may be that its apparent rarity is due to lack of recognition. McClatchie and Bremner (1969) stressed that cases of tumoral calcinosis masquerade under various pseudonyms such as calcified bursa, calcified lipoma, and metastatic calcification. There is a distinct clinical picture, however, and the histology is characteristic if not diagnostic. In addition, familial cases and biochemical abnormalities in patients and their asymptomatic relatives point to tumoral calcinosis as a distinct entity.

Tumoral calcinosis presents as swelling about joints. The swelling may be solitary and slow growing or multiple with rapid growth. The commonest sites for the tumour are about the hip, elbow, shoulder, and the gluteal muscles, but may occur in many other sites. The swellings occur in the subcutaneous tissues but may also be deep in the muscle planes. The masses are of variable size and hard on palpation but may occasionally feel cystic. Sinus formation is uncommon but when it occurs may be associated with discharge of white chalk-like debris. The masses are not usually accompanied by pain or tenderness but may cause such symptoms by pressure on local nerves (Riemenschneider and Ecker, 1952).

Radiologically, calcification is universal, showing initially as small discrete calcified nodules progressing to large lobulated calcified tumours. They do not affect the adjacent joint (Palmer, 1969).

The pathological appearance of these lesions is of a septate cystic mass, the septae formed by thick bands of fibrous and granulation tissue, with the intervening cisterns full of a semisolid, chalk-like material with a granular structureless appearance and which stains positively for calcium. Chemical analysis of this material in case 1 has shown it to consist of calcium phosphate. Other analyses have shown calcium phosphate alone, or a mixture of calcium phosphate and carbonate (Lafferty et al., 1969).

The serum biochemistry in tumoral calcinosis may be ab- normal as in case 1. Lafferty et al., in their review of 18 previously recorded cases, pointed out that while serum calcium and alkaline phosphatase levels were normal the serum phosphorus was increased in five of 13 patients in whom these estimations were made. Moreover, it is interesting to note that the disease may be familial with clinical lesions presenting in sibs, or healthy sibs may have only biochemical abnormalities.

Nothing definite is known of the aetiology of tumoral calcinosis. The geographical distribution and subcutaneous calcification have suggested a reaction to parasites, particularly onchocerca, but the widespread occurrence of the lesion in areas where simulium is absent rule this out (McClatchie and Bremner, 1969). Moreover, no parasitic remnants have been described in association with lesions showing the characteristic histology.

Trauma has been alleged to be a causal factor, and predominance about hips and buttocks has been ascribed to sleeping on the floor or hard beds. Thomson and Tanner (1949) described a case of a Negro "bronchobuster" who had received a kick from a horse and whose two brothers had previously been treated for the disease. Owor (1972), however, stresses that in many of the Ugandan cases the lesions were situated in sites where trauma is minimal.

The frequent raised levels of serum phosphorus and the occurrence of the disease or serum abnormalities among sibs suggest that tumoral calcinosis may be an inborn error of metabolism. Lafferty et al. (1965) made calcium, nitrogen, and phosphorus balance studies in one case but were unable to specify an exact abnormality. It is interesting to speculate that a metabolic variation, perhaps with increased frequency in the coloured races, might predispose to the development of lesions at sites of repeated trauma.

We wish to thank Mr. A. G. Cox for clinical details of Case 2 and Mr. G. Padmore for the biochemical results. We thank Miss B. Pentland for her typing.

\section{References}

Berg, B. (1972). British fournal of Surgery, 59, 570. Inclan, A. (1943). Fournal of the American Medical Association, 121, 490. Lafferty, F. W., Reynolds, E. S., and Pearson, O. H. (1965). American Fournal of Medicine, 38, 105.

McClatchie, S., and Bremner, A. D. (1969). British Medical fournal, 1, 153.

Maegraith, B. (1971). Practitioner, 206, 816

Owor, R. (1972). Tropical and Geographical Medicine, 24, 39.

Palmer, P. E. S. (1966). British fournal of Radiology, 31, 104

Palmer, P. E. S. (1969). Quoted by McClatchie and Bremner (1969).

Riemenschneider, P. A., and Ecker, A. (1952). Fournal of Neurosurgery, 9 304.

Thomson, J. E. M., and Tanner, F. H. (1949). fournal of Bone and foint Surgery, 31A, 132.

\section{Enzyme Typing of Malaria Parasites}

\section{R. CARTER, A. VOLLER}

British Medical fournal, 1973, 1, 149-150

\section{Summary}

Analysis of various isolates of Plasmodium falciparum from East and West Africa and from South-east Asia showed that some of the parasite enzymes can exist in

Protozoan Genetics Unit, Institute of Animal Genetics, Edinburgh R. CARTER, PH.D., Research Associate

Nuffield Institute of Comparative Medicine, Zoological Society of London, London N.W.1

A. VOLLER, D.sc., Senior Lecturer more than one electrophoretic form. At least one form of each enzyme was common to parasites from all three regions. The enzyme forms could be used to differentiate morphologically indistinguishable samples of $P$. falciparum.

\section{Introduction}

Malignant tertian malaria, caused by infection of man by Plasmodium falciparum, is widely distributed throughout the tropical areas of the world. In spite of the fact that "strains" isolated from within and between different geographical regions differ in their immunological characteristics, in drug sensitivity, 